\title{
Erratum to: Endoscopic management of post-laparoscopic sleeve gastrectomy stenosis
}

\author{
Salman Al Sabah ${ }^{1,2}$ (1) Eliana Al Haddad ${ }^{1}$ Iqbal Siddique ${ }^{1,2}$
}

Published online: 19 May 2017

(c) Springer Science+Business Media New York 2017

\section{Erratum to: Surg Endosc}

DOI 10.1007/s00464-016-5385-9

Inadvertently omitted from the author group was a third author, Iqbal Siddique, whose affiliations are Al Amiri Hospital, Kuwait City, Kuwait, and Department of Medicine, Faculty of Medicine, Kuwait University, Kuwait.

The original article was corrected.

The online version of the original article can be found under doi:10.1007/s00464-016-5385-9.

Salman Al Sabah

salman.k.alsabah@gmail.com

Eliana Al Haddad

eliana.h91@gmail.com

$1 \quad$ Al Amiri Hospital, Kuwait City, Kuwait

2 Department of Medicine, Faculty of Medicine, Kuwait University, Kuwait City, Kuwait 